\title{
Editorial
}

\section{Methods for the prediction of coronary heart disease risk}

It is indisputable that patients with coronary heart disease (CHD) should generally receive statin treatment, certainly if their serum cholesterol exceeds $5 \mathrm{mmol} / 1 .{ }^{1}$ Patients with peripheral arterial disease or stroke are at a similar level of risk of a subsequent CHD event as are the survivors of myocardial infarction and are also increasingly recommended to receive statin treatment. ${ }^{2}$

\section{Coronary risk in primary prevention}

How to use statins in the primary prevention of CHD, however, remains controversial. The difficulty is not a lack of evidence of the clinical effectiveness of statins in primary prevention; this was established in the West of Scotland coronary prevention study ${ }^{3}$ and the Air Force/Texas coronary atherosclerosis prevention study. ${ }^{4}$ Rather it is that there are so many people who could benefit from statin treatment, particularly in Britain, which internationally has one of the worst records for CHD deaths. The cost of treating all those who can benefit would be enormous and require major adjustments to the use of other less cost effective treatment, if it were to be accommodated within the existing National Health Service (NHS) budget. Thus, while the scientific evidence of benefit for statin treatment extends to people with a 10 year CHD risk of less than $10 \%,{ }^{4}$ the NHS framework on CHD prevention recommends the use of statins in primary prevention only when the CHD risk reaches $30 \%$ over 10 years. ${ }^{5}$ The Joint British Societies (British Cardiac Society, British Diabetic Association, British Hyperlipidaemia Association) recommended statin treatment in primary prevention in people whose 10 year CHD risk exceeds $15 \%$, which is clearly evidence based. ${ }^{2}$ The Joint European Task Force on Coronary Prevention recommended $20 \%{ }^{6}$ This is the level which is cost effective at current statin prices. ${ }^{7}$ Our study, ${ }^{8}$ comparing the US National Cholesterol Education Program (NCEP) recommendations ${ }^{9}$ with both the British and European ones, revealed that in the USA the intention was plainly to initiate statin treatment at substantially lower levels of CHD risk than in Europe.

If CHD risk is to form the basis of clinical decisions about the use of statin treatment, the clinician must be provided with a means of assessing that risk. This is further emphasised by the recent recommendations about the treatment of hypertension, which it is also considered should be increasingly based on cardiovascular risk rather than simply on blood pressure per se. Thus the British Hypertension Society already recommends that antihypertensive treatment for primary prevention is prescribed only when the 10 year CHD risk exceeds $15 \%$ for patients whose blood pressure is in the range 140/90-159/ $99 \mathrm{~mm} \mathrm{Hg} .{ }^{10}$

\section{Charts and tables in coronary risk prevention}

In the article by Jones and colleagues published recently in Heart, eight methods, which have been proposed for CHD (or cardiovascular disease) risk prediction, were compared in a population of patients whose general practitioners wished to assess risk. ${ }^{11}$ The methods were all based on the Framingham risk equation, because this remains the only published epidemiological study in which there are both men and women and in which a reasonably comprehensive range of risk factors was measured. ${ }^{12}$ The overall best method in terms of how closely its results matched the original equation was the Joint British Societies coronary risk prediction charts, ${ }^{213}$ which is gratifying to those of us who designed them, coming as it does from an independent source. The need for the Joint British Societies charts was created by the inaccuracy in the Sheffield tables, ${ }^{14}$ which was unknown until they were subjected to clinical trial. ${ }^{8}$ Unfortunately by then their use had been advised by the standing medical advisory committee (SMAC) to the chief medical officer of health. ${ }^{15}$ The New Zealand charts, ${ }^{16}$ which were recommended by SMAC as a possible alternative to the Sheffield tables, are also revealed by the study by Jones and colleagues ${ }^{11}$ to be less accurate than the Joint British Societies charts. So also are the European ones. ${ }^{6}$ These findings are confirmed by our own unpublished results in the population, which we previously studied in the evaluation of the NCEP algorithm, the European charts, and the original Sheffield tables ${ }^{8}$ (table 1).

The Joint British Societies charts are available as a leaflet or as a wall chart from the British Heart Foundation (telephone 02074877142 ) and are to be found at the back of the British National Formulary.

\section{HDL cholesterol and primary prevention}

It is particularly important to note that the study of Jones and colleagues ${ }^{11}$ once again underlines the importance of measuring high density lipoprotein (HDL) cholesterol as well as total serum cholesterol in the assessment of risk in primary prevention. This is because, as risk factors multiply, HDL cholesterol concentrations fall (fig 1). Thus the people who are at most risk often fail to be identified unless the additional risk from their low HDL cholesterol is taken into account. ${ }^{8}$ The necessity to measure HDL cholesterol is made more emphatic in Britain by the high level of risk which is being advocated before statins can be employed. This is because the inaccuracy of predicting CHD risk without measuring HDL cholesterol becomes progressively greater as higher risk groups are targeted (fig 2). It is probably not widely enough appreciated that the measurement of HDL cholesterol can be undertaken on nonfasting samples ${ }^{2}$ (unlike the measurement of triglycerides

Table 1 The number ( $n$ ) of patients from a population of 386 referred to a lipid clinic to whom the various charts or tables could be applied, whose risk was correctly classified according to the Framingham risk equation ${ }^{12}$ risk was correctly classified

\begin{tabular}{|c|c|c|c|c|}
\hline & $n$ & $\begin{array}{l}\text { Correct } \\
(\%)\end{array}$ & $\begin{array}{l}\text { Underestimated } \\
\text { (\%) }\end{array}$ & $\begin{array}{l}\text { Overestimated } \\
(\%)\end{array}$ \\
\hline$\overline{\text { Joint British charts (Heart version) }}{ }^{2}$ & 340 & 87.9 & 5.0 & 7.1 \\
\hline Joint British charts (BMJ version) $)^{13}$ & 307 & 88.3 & 5.5 & 6.2 \\
\hline New Zealand charts ${ }^{16}$ & 230 & 63.0 & 2.2 & 34.8 \\
\hline Joint European charts ${ }^{6}$ & 262 & 65.6 & 6.5 & 27.9 \\
\hline New Sheffield tables ${ }^{17}$ & 322 & 81.1 & 5.9 & 13.0 \\
\hline
\end{tabular}

Coronary heart disease risk was calculated using the Framingham risk equation $^{12}$ except in the case of the New Zealand charts when cardiovascular risk, which they are designed to predict, was calculated.

The percentages are for the patients (n) to whom the charts or tables could be applied. 


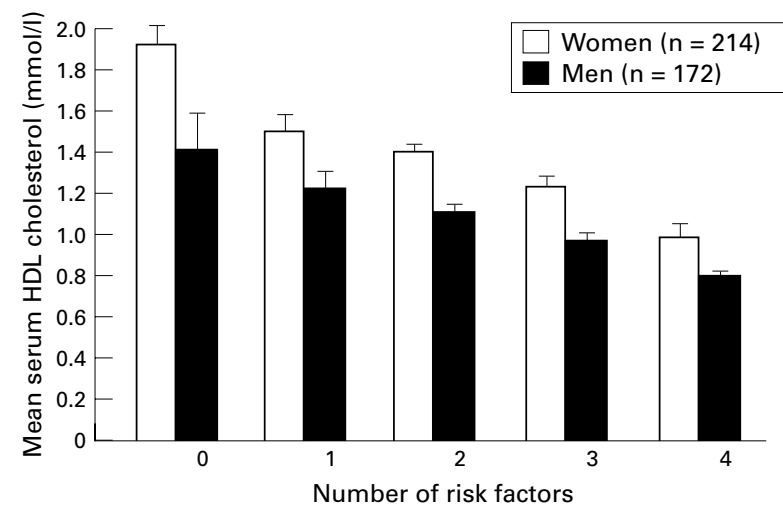

Figure 1 Mean (SE) serum HDL cholesterol in men and women according to the number of CHD risk factors they had. ${ }^{8}$

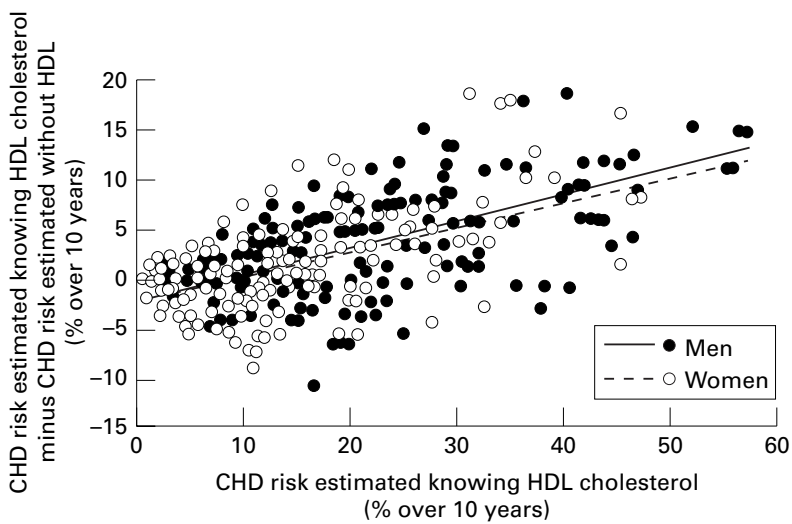

Figure 2 CHD risk computed with a knowledge of the patients' HDL cholesterol concentrations plotted against the risk calculated with knowing individual HDL cholesterol concentrations. ${ }^{8}$

or of low density lipoprotein (LDL) cholesterol when this is calculated, as it is in most laboratories, from the fasting triglycerides, serum cholesterol, and HDL cholesterol). It is not generally necessary, however, to measure HDL cholesterol in secondary prevention (when a serum cholesterol of $5.00 \mathrm{mmol} / 1$ or greater is taken as the indication for statin treatment) nor in the monitoring of patients once the decision to introduce such treatment has been taken. ${ }^{2}$

\section{Computer assisted risk prediction}

The results of Jones and colleagues ${ }^{11}$ indicate that further development in chart design is unlikely. The only improvement possible is for the clinician to use a computer programme to calculate CHD risk. The Joint British Societies' recommendations already recognise this, which is why the "Cardiac risk assessor" computer program was issued with each of the Heart supplements containing the recommendations. ${ }^{2}$ The program is also available from the British Heart Foundation and from the present authors, and it is on the British Hypertension Society website (www.hyp.ac.uk/bhs) and the British National Formulary website (http://bnf.org). In addition to the information provided by the charts, the computer program also allows left ventricular hypertrophy to be taken into account and provides both coronary and stroke risk based on systolic and diastolic blood pressures.

P N DURRINGTON H PRAIS

Department of Medicine,

Manchester Royal Infirmary,

Oxford Road,

Manchester M13 9WL,

UK

pdurrington@hq.cmht.nwest.nhs.uk

1 Hebert PR, Gaziano JM, Chan KS, et al. Cholesterol lowering with statin drugs, risk of stroke, and total mortality. An overview of randomised trials. drugs, risk of stroke, and $1997 ; 278: 313-21$.

2 Wood D, Durrington PN, Poulter N, et al. Joint British recommendations on prevention of coronary heart disease in clinical practice. Heart 1998; prevention of coro

3 Shepherd J, Cobbe SM, Ford I, et al for the West of Scotland Coronary Prevention Study Group. Prevention of coronary heart disease with pravastatin in men with hypercholesterolaemia. N Engl F Med 1995;333:1301-7.

4 Downs GR, Clearfield M, Weiss S, et al. Primary prevention of acute coronary events with lovastatin in men and women with average cholesterol levels: results of the AFCAPS/TEXCAPS (Air Force/Texas coronary atherosclerosis prevention study). $\mathcal{F} A M A$ 1998;279:1615-22.

5 Department of Health. National service framework for coronary heart disease: modern standards and service. London: Department of Health, 2000.

6 Wood D, De Backer G, Faergeman O, et al, with members of the Task Force. Prevention of coronary heart disease in clinical practice: recommendations of the second joint task force of European and other societies on coronary prevention. Atherosclerosis 1998;140:199-270.

7 Reckless JPD. Cost-benefit analysis of lipid lowering management. In: Betteridge DJ, Illingworth DR, Shepherd J, eds. Lipoproteins in health and disteridge DJ, Illingworth DR, Shepherd
ease. London: Arnold. 1999:1230-54.

8 Durrington PN, Prais H, Bhatnagar D, et al. Indications for cholesterollowering medication: comparison of risk-assessment methods. Lancet 1999;353:278-81.

9 Expert Panel on Detection, Evaluation and Treatment of High Blood Cholesterol in Adults. Summary of the second report of the national cholesterol education program (NCEP) Expert panel on detection, evaluation and treatment of high blood cholesterol in adults (adult treatment panel II). FAMA 1993;269:3015-23.

10 Ramsay LE, Williams B, Johnston GD, et al. Guidelines for management of hypertension: report of the third working party of the British Hypertension Society. F Human Hypertens 1999;13:569-92.

11 Jones AF, Walker J, Jewkes C, et al. Comparative accuracy of cardiovascular risk prediction methods in primary care patients. Heart 2001;85:37-43.

12 Anderson KM, Odell PM, Wilson PWF, et al. Cardiovascular disease risk profiles. Am Heart f 1990;121:293-8.

13 British Cardiac Society, British Hyperlipidaemia Association, British Hypertension Society, British Diabetic Association. Joint British recommendations on prevention of coronary heart disease in clinical practice: summary. BMf 2000;320:705-8.

14 Haq IU, Ramsay LE, Pickin JN, et al. Lipid lowering for prevention of coronary heart disease: what policy now? Clin Sci 1996;91:399-413.

15 NHS Executive. Standing medical advisory committee statement on the use of statins, executive letter EL(97)41. Wetherby: Department of Health, 1997.

16 Dyslipidaemia Advisory Group, on behalf of the Scientific Committee of the National Heart Foundation of New Zealand. 1996 National Heart Foundation guidelines for the assessment and management of dyslipidaemia. N Z Med F 1996;109:224-32.

17 Wallis EJ, Ramsay LE, Haq IU, et al Coronary and cardiovascular risk estimation for primary prevention: validation of the new Sheffield table in the 1995 Scottish health survey populations. BMF 2000;320:671-6. 